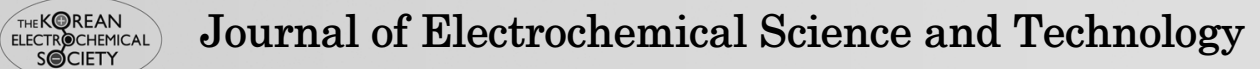
jecst.org

\title{
A Review of Industrially Developed Components and Operation Conditions for Anion Exchange Membrane Water Electrolysis
}

\author{
Ahyoun $\mathrm{Lim}^{1,2}$, Min Kyung Cho ${ }^{1}$, So Young Lee ${ }^{1}$, Hyoung-Juhn Kim ${ }^{1}$, Sung Jong Yoo ${ }^{1}$, \\ Yung-Eun Sung ${ }^{2,4 * * *}$, Jong Hyun Jang ${ }^{1,3, * *}$, and Hyun S. Park ${ }^{1, *}$ \\ ${ }^{1}$ Fuel Cell Research Center, Korea Institute of Science and Technology (KIST), Seoul 02792, Republic of Korea \\ ${ }^{2}$ School of Chemical and Biological Engineering, Seoul National University, Seoul 08826, Republic of Korea \\ ${ }^{3}$ Green School, Korea University, Seoul 02841, Republic of Korea \\ ${ }^{4}$ Center for Nanoparticle Research, Institute for Basic Science (IBS), Seoul 08826, Republic of Korea
}

\begin{abstract}
Solid-state alkaline water electrolysis is a promising method for producing hydrogen using renewable energy sources such as wind and solar power. Despite active investigations of component development for anion exchange membrane water electrolysis (AEMWE), understanding of the device performance remains insufficient for the commercialization of AEMWE. The study of assembled AEMWE devices is essential to validate the activity and stability of developed catalysts and electrolyte membranes, as well as the dependence of the performance on the device operating conditions. Herein, we review the development of catalysts and membranes reported by different AEMWE companies such as ACTA S.p.A. and Proton OnSite and device operating conditions that significantly affect the AEMWE performance. For example, $\mathrm{CuCoO}_{x}$ and $\mathrm{LiCoO}_{2}$ have been studied as oxygen evolution catalysts by Acta S.p.A and Proton OnSite, respectively. Anion exchange membranes based on polyethylene and polysulfone are also investigated for use as electrolyte membranes in AEMWE devices. In addition, operation factors, including temperature, electrolyte concentration and acidity, and solution feed methods, are reviewed in terms of their influence on the AEMWE performance. The reaction rate of water splitting generally increases with increase in operating temperature because of the facilitated kinetics and higher ion conductivity. The effect of solution feeding configuration on the AEMWE performance is explained, with a brief discussion on current AEMWE performance and device durability.
\end{abstract}

Keywords : Water electrolysis, Anion exchange membrane, Electrocatalyst, Membrane electrode assembly

Received : 10 August 2017, Accepted : 25 September 2017

\section{Introduction}

The unpredictable environmental events and serious societal and industrial impacts caused by global warming necessitates the establishment of a sustainable economy with zero carbon emissions using renewable and sustainable energy sources [1]. Hydrogen $\left(\mathrm{H}_{2}\right)$ is a clean energy carrier that can replace fossil fuels in a carbon-free economy [2]. The production of $\mathrm{H}_{2}$ without greenhouse gas emissions can be achieved using

*E-mail address: hspark@kist.re.kr

**E-mail address: jhjang@kist.re.kr

***E-mail address: ysung@snu.ac.kr

DOI: https://doi.org/10.5229/JECST.2017.8.4.265 renewable-energy-driven $\mathrm{H}_{2}$ generation techniques $[3,4]$. Among such techniques, water electrolysis is a possible route to realize zero-carbon, high-purity, and high-pressure $\mathrm{H}_{2}$ production [5].

The reaction fundamentals $[6,7]$ and device applications [3,8-10] of electrochemical water splitting have been studied extensively to develop an energyefficient and economic electrolysis system. Water electrolysis systems can be divided into three categories based on the electrolyte used: (i) alkaline electrolyte, (ii) solid oxide electrolyte, and (iii) polymer electrolyte membrane (PEM) water electrolysis [8]. Alkaline water electrolysis using diaphragm separators is a mature technology of more than 200 years 
old and has been implemented industrially for commercial $\mathrm{H}_{2}$ production for over 50 years [11]. It utilizes cheap and robust electrode materials, such as $\mathrm{Ni}$ and $\mathrm{Fe}$, for the oxygen evolution reaction (OER) in basic aqueous solutions, which could be more favorable than that in acidic or neutral solutions [10]. The energy conversion efficiency of alkaline water electrolysis can reach $70 \%$ with an $\mathrm{H}_{2}$ production pressure of $35 \mathrm{MPa}$ [10]. Solid oxide water electrolysis uses ion-conducting ceramics at high temperatures of 600$900^{\circ} \mathrm{C}$ as electrolytes. Their high-temperature operation allows fast electrolysis kinetics for both $\mathrm{H}_{2}$ and $\mathrm{O}_{2}$ evolution, and cheap metal (oxide) catalysts can be used as electrode materials [12]. However, neither liquid electrolysis devices employing porous diaphragms nor solid oxide devices allow rapid on/off operation or significant pressure differences between two $\mathrm{H}_{2}$ and $\mathrm{O}_{2}$ evolution chambers because of the severe gas crossover through the separator or electrolyte $[13,14]$.

Polymer electrolyte membrane water electrolysis (PEMWE) uses ion-conducting polymer membranes as the electrolyte instead of liquids or ceramic conductors. PEMWE provides improved energy efficiency reaching $82 \%$, fast start/stop operation, and high $\mathrm{H}_{2}$ production pressure reaching $70 \mathrm{MPa}[3,15]$. The majority of commercialized PEMWE is currently constructed using proton-exchange membranes with reported maximum device lifetimes of $100,000 \mathrm{~h}$; the typical lifetime is 5,000-20,000 $\mathrm{h}$ [16]. Water-splitting reactions are performed by feeding neutral or acidic electrolyte solutions to electrodes placed on both sides of the proton-conducting membrane. PEMWE has the advantageous capability to produce high-purity $\mathrm{H}_{2}$ using intermittent external power sources, and MW-scale PEMWE devices have been commercialized by several companies including CETH2, ITM Power, Hydrogenics, Proton Onsite, and Siemens. However, $\mathrm{H}_{2}$ production by PEMWE costs more than three times that from steam reforming, at approximately $\$ 5.1$ and $\$ 1.5 / \mathrm{kg}_{\mathrm{H} 2}$ as of 2014 for electrolysis and chemical reforming, respectively [17].

The $\mathrm{H}_{2}$ production cost of PEMWE can be reduced while maintaining the advantages of the polymer membrane reactor if the membrane electrolysis device can be efficiently operated under alkaline conditions, such that an activity comparable to that of proton-exchange membrane devices is achieved [11]. Sluggish OER kinetics is the dominant factor limiting the overall water electrolysis performance, requiring precious metal oxides, such as $\mathrm{IrO}_{2}$ or $\mathrm{RuO}_{2}$, at the anode under acidic or neutral environments [3]. However, the OER can be more activated in alkaline condition than in acidic and neutral media, and nonprecious metal oxide catalysts could be used for costeffective anodes in anion-exchange membrane water electrolysis (AEMWE) working under alkaline environments [18]. Many efforts to achieve cost-effective AEMWE have been made by developing highly active hydrogen evolution reaction (HER) and OER catalysts and highly conductive anion-exchange membranes with sufficient mechanical and chemical robustness under alkaline conditions [19,23]. Among the non-Pt-group metal (non-PGM) HER catalysts that are active in alkaline media, Ni-based alloys, such as $\mathrm{Ni}-\mathrm{Mo}$ and $\mathrm{Ni}-\mathrm{Cr} / \mathrm{C}$, are considered promising candidates with high activity and stability $[20,21]$. For alkaline OER catalysts, transition-metal oxides, e.g., oxides of $\mathrm{Fe}, \mathrm{Co}$, $\mathrm{Ni}$, and $\mathrm{Mn}$, exhibit promising stability and activity as alternatives to noble-metal OER catalysts [22, 23]. $\mathrm{NiCoO}_{2}$ shows OER activity similar to that of $\mathrm{IrO}_{2}$ and $\mathrm{RuO}_{2}$ in benchmarking half-cell tests of nanoparticle metal oxides [22]. In the development of anion-conducting membranes, membranes based on polysulfone (PSF), polyphenylene, and polybenzimidazole showed improved stability, conductivity, and cost-effectiveness [24]. Linear and cross-linked polybenzimidazoles have been evaluated and found to show high hydroxide ion conductivity of $10 \mathrm{mS} / \mathrm{cm}$ and high structural stability [23].

Both device operation and material development must be investigated for successful commercialization of AEMWE, because various operational factors including pressure, temperature, and electrolyte acidity can significantly affect the overall performance of AEMWE devices [24-26]. Single-cell testing or device investigation allows direct examination of the developed electrode components, such as catalysts and membranes, including the fabrication processes of membrane-electrode assemblies (MEA) under various operating conditions. The relationships between device performance, component properties, and operating conditions can be determined through cell operation in two-electrode devices. In addition, the performance of actual devices can differ significantly from that at the component level because the full-cell reactions are affected by complex ion- and mass-transport phenomena in the MEA. In addition, certain aspects of AEMWE devices can only be 
assessed by observations at the MEA level. For example, MEA degradation during the start and stop cycles, accompanied by catalyst loss, membrane decomposition, or catalyst layer delamination, can only be determined through single-cell tests [27]. However, only a few studies on developing AEMWE materials have experimentally proven the performance of single-cell devices.

Herein we review the industrial reaserch and operation conditions of AEMWE for practical $\mathrm{H}_{2}$ production. As mentioned above, device evaluation is imperative to efficiently utilize the active components developed for AEMWE, while operational conditions significantly affect device performance. Therefore, we first review the materials and operation conditions reported in studies performed by Acta S.p.A. and Proton OnSite, two companies distributing commercial AEMWE devices [11,24,25,27,28]. Next, factors that significantly influence cell performance are reviewed, including operating temperatures [24, 28], concentration or acidity of electrolyte solutions [24, 25], and solution feed configurations [26]. AEMWE studies conducted via single-cell tests are reviewed in the hope of providing ideas for testing developed materials in the reliably performing single-cell configuration.

\section{AEMWE Research in Industry}

\subsection{Acta S.p.A}

Acta S.p.A (ACTA) produces water electrolysis equipment, including AEMWE devices that are capable of generating 100-1000 L of high purity $\mathrm{H}_{2}$ per hour at $3 \mathrm{MPa}$ without mechanical drying or compressing apparatus. This scale is similar to the production rate and cost of alkaline water electrolysis. In published studies, the company also reported the development of cost-effective non-PGM catalysts and AEMs for AEMWE as described below.

ACTA provides the non-precious commercial catalysts ACTA 4030 and ACTA 3030 for the HER and OER, respectively, in alkaline conditions [29]. The water-splitting activity and stability of an AEMWE device were reported using the commercialized materials $\mathrm{Ni} /\left(\mathrm{CeO}_{2}-\mathrm{La}_{2} \mathrm{O}_{3}\right) / \mathrm{C}(\mathrm{HER})$ and $\mathrm{CuCoO}_{\mathrm{x}}(\mathrm{OER})$ under mildly alkaline conditions with various HER catalyst amounts, electrolytes, and operation temperatures [24]. An MEA built using an A-201 AEM (Tokuyama) showed stable performance in an AEMWE single-cell test conducted with a controlled amount of HER catalyst (ACTA 4030) at $43^{\circ} \mathrm{C}$ [24]. At a current density of $470 \mathrm{~mA} / \mathrm{cm}^{2}$, the cell voltage varied from 2.01 to $1.89 \mathrm{~V}$ as the loading of HER catalyst was increased from 0.6 to $7.4 \mathrm{mg} / \mathrm{cm}^{2}$ (Fig. 1(a)). Though slow OER kinetics are known to dominate the cell overpotential in water electrolysis, the results indicated a non-negligible contribution from the cathode activity to the cell performance.

In a 2014 study, a dilute carbonate/bicarbonate aqueous solution ( 1 wt. $\% \mathrm{~K}_{2} \mathrm{CO}_{3} / \mathrm{KHCO}_{3}$ and $1 \mathrm{wt} . \%$ $\mathrm{K}_{2} \mathrm{CO}_{3}$ ) was chosen as the basic electrolyte for the feeding solution [24] because a lower-pH solution
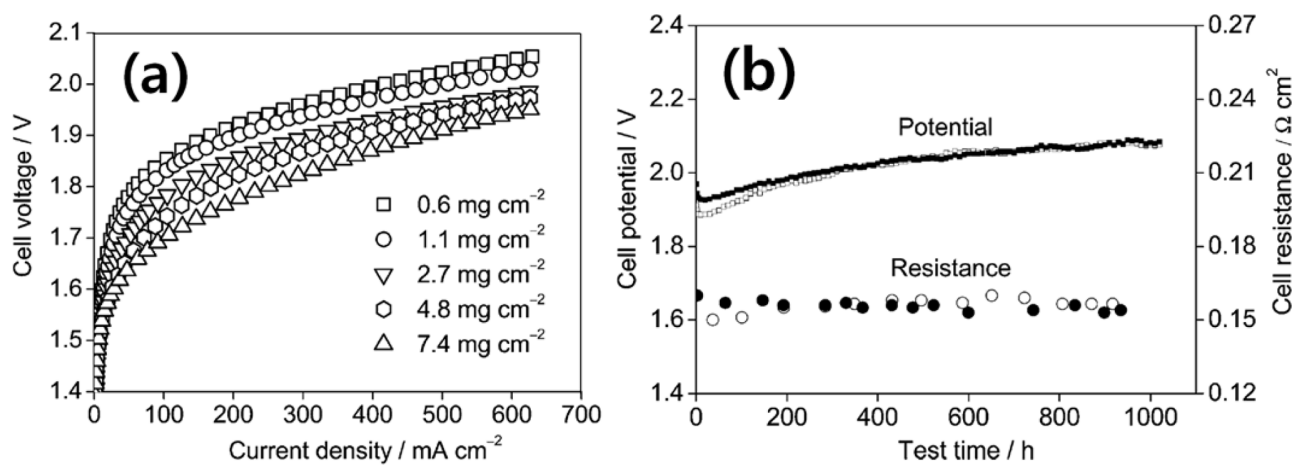

Fig. 1. (a) Polarization curves recorded after a 24-h test run for an AEMWE cell containing MEAs with different HER catalyst loading levels. (b) Long-term performance and AC resistance $(1 \mathrm{kHz})$ of AEMWE cells at $3 \mathrm{MPa}$ operating with 1 wt.\% $\mathrm{K}_{2} \mathrm{CO}_{3} / \mathrm{KHCO}_{3}$ (solid symbol) and $1 \mathrm{wt} . \% \mathrm{~K}_{2} \mathrm{CO}_{3}$ (open symbol) electrolyte solutions. Tests were performed on cells with HER catalyst loading of $7.4 \mathrm{mg} / \mathrm{cm}^{2}$, at constant current density of $470 \mathrm{~mA} / \mathrm{cm}^{2}$ and $4{ }^{\circ} \mathrm{C}$ (reproduced from ref. [24] with permission from Wiley-VCH). 
( $\mathrm{pH}$ 10-11) was expected to cause less AEM degradation than a higher-pH KOH solution ( $\mathrm{pH} 12-14)$. In addition, the $\mathrm{K}_{2} \mathrm{CO}_{3}$ electrolyte is less affected by $\mathrm{CO}_{2}$ contamination than $\mathrm{KHCO}_{3}$, where carbonization reduces the ionic conductivity of the electrolyte solution. Therefore, the cost of sealing to avoid carbonation was eliminated. The $1 \mathrm{wt} . \% \mathrm{~K}_{2} \mathrm{CO}_{3}$ solution had a higher initial $\mathrm{pH}(11.2)$ than that of the $1 \mathrm{wt} . \%$ $\mathrm{K}_{2} \mathrm{CO}_{3} / \mathrm{KHCO}_{3}$ solution (10.2); the cell performance using the $1 \mathrm{wt} . \% \mathrm{~K}_{2} \mathrm{CO}_{3}$ electrolyte was slightly higher than that of the cell employing the initial $1 \mathrm{wt} . \%$ $\mathrm{K}_{2} \mathrm{CO}_{3} / \mathrm{KHCO}_{3}$ mixture (Fig. 1(b)). However, the electrolyte basicity and cell performance of the two electrolysis devices became similar after $300 \mathrm{~h}$ of operation, reportedly by the slight carbonation of the 1 wt. $\% \mathrm{~K}_{2} \mathrm{CO}_{3}$ solution during operation. Stability testing was done at a constant differential pressure of $3 \mathrm{MPa}$ for both systems; the cell potential reached $2.01 \mathrm{~V}$ from around $1.9 \mathrm{~V}$ after $1000 \mathrm{~h}$ of operation (Fig. 1(b)).

The ionic conductivity and stability are critical in membrane development for AEMWE. Only a few AEMs have been studied in a single cell configuration [9]. In the AEM development reported by ACTA, a low-density polyethylene (LDPE)-based membrane with UV-induced grafted vinylbenzyl chloride (VBC) functional monomers and 1,4-diazabicyclo(2.2.2) octane (DABCO), referred to as LDPE-g-VBC-DABCO, was synthesized and compared to the commercial A201 Tokuyama membrane [30]. The PE membrane was studied to determine potential cost-effective and robust electrolytes for AEMWE. In the study, single-cell testing was performed at $45^{\circ} \mathrm{C}$ in a $1-w t . \% \mathrm{~K}_{2} \mathrm{CO}_{3}$ electrolyte. However, the MEA using the LDPE-g-VBC-DABCO still showed an overvoltage $80 \mathrm{mV}$ higher than that of the commercial membrane-based MEA at $600 \mathrm{~mA} / \mathrm{cm}^{2}$ for $\mathrm{H}_{2}$ generation at $2 \mathrm{MPa}$ (Fig. 2(a)). In long-term performance tests $(500 \mathrm{~h})$, the LDPE-g-VBCDABCO-based MEA also showed an increase in cell resistance by approximately $43 \%$ (from 30 to $43 \mathrm{~m} \Omega$ ), whereas the commercial A201-based MEA displayed an insignificant increase in cell resistance in the stability test [30].

\subsection{Proton OnSite}

Proton OnSite (Proton) is one of the biggest PEMWE companies in the world, and the proton exchange membrane water electrolysis device developed by the company can produce $400,000 \mathrm{~L} \mathrm{H}_{2} / \mathrm{h}$ at a delivery pressure of $3 \mathrm{MPa}$ [31]. Recently, Proton reported AEMWE research toward constructing a water electrolysis system more economical than proton exchange membrane water electrolysis [13,32,33]. Non-PGM catalysts, membranes, and flow-field materials can be cheaper for AEMWE systems, because AEMWE allows alternatives, such as stainless steel or $\mathrm{Ni}$, which can be operated under basic conditions, to conventional expensive flow field materials, such as Ti, which is used for acidic environments. The approach taken by Proton has three
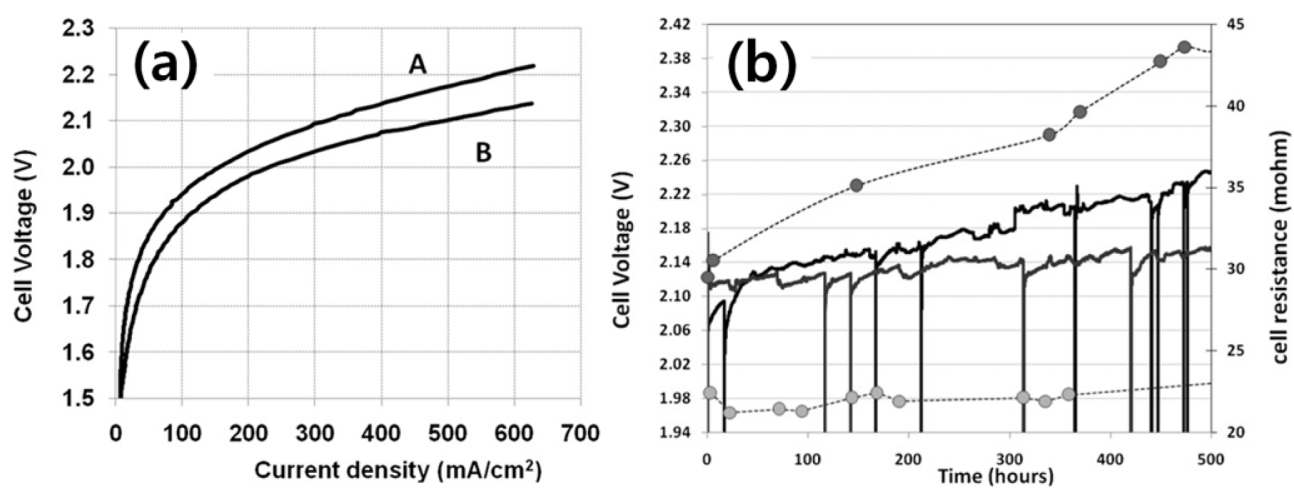

Fig. 2. (a) Current-voltage curves measured during water electrolysis using LDPE-g-VBC-DABCO MEA (A) and the A201 MEA (B) at $\mathrm{T}_{\text {cell }}$ of $45^{\circ} \mathrm{C}$ and the scan rate of $1 \mathrm{mV} / \mathrm{s}$. (b) Time stability test of electrolysis device at a constant current density of $460 \mathrm{~mA} / \mathrm{cm}^{2}$ : LDPE-g-VBC- DABCO MEA (continuous upper line) and A201 MEA (lower continuous line). The AC cell resistance at $1 \mathrm{kHz}$ is shown on the right-hand $y$-axis for the LDPE-g-VBC- DABCO cell (dark circles) and the A201 cell (light circles). $\mathrm{T}_{\text {cell }}$ was $45^{\circ} \mathrm{C}$ with an $\mathrm{H}_{2}$ outlet pressure of $2 \mathrm{MPa}$ (reproduced from ref. [30] with permission from Elsevier). 

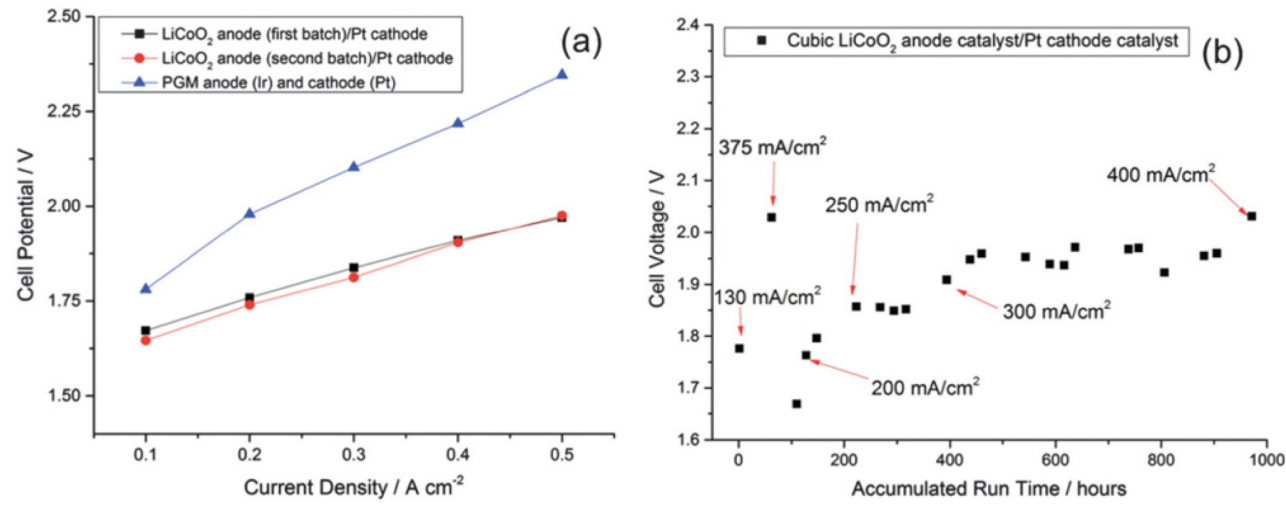

Fig. 3. $\mathrm{LiCoO}_{2}$ performance as an anodic catalyst in AEMWE. (a) Polarization curve showing favorable efficiency compared to an $\mathrm{IrO}_{x}$-based anode $\left(0.3 \mathrm{~V}\right.$ lower at $\left.500 \mathrm{~mA} / \mathrm{cm}^{2}\right)$ and reproducibility of activity. (b) Run time-averaged operating potential for a single cell stepped to different current densities (reproduced from ref. [33] with permission from the Royal Society of Chemistry).

main themes: (1) developing good non-PGM OER catalysts, (2) processing and assembling effective MEAs, and (3) improving cell design [32].

In a non-PGM catalyst research collaboration with Rutgers University, cubic $\mathrm{LiCoO}_{2}$ (or $\mathrm{LiCo}_{2} \mathrm{O}_{4}$ ), discovered as an OER catalyst, outperformed PGM catalysts in AEMWE [33]. The resulting continuously operated AEMWE was stable for $1000 \mathrm{~h}$ at a current density of $400 \mathrm{~mA} / \mathrm{cm}^{2}$ at $50^{\circ} \mathrm{C}$. In addition, the cubic $\mathrm{LiCoO}_{2}$ produced a lower overpotential for the OER than that of PGM catalysts, such as Ir or Co oxides (Fig. 3) [33] The cubane $\left[\mathrm{Co}_{4} \mathrm{O}_{4}\right]^{\text {nt }}$ unit present in cubic or spinel Co oxide crystals was considered to be the active catalytic center for multi-electron transfer reactions with sufficient conductivity and stability. As shown in Fig. 3, the use of $\mathrm{LiCoO}_{2}$ in an AEMWE device led to superior oxygen evolution activity compared to that using an $\mathrm{Ir} / \mathrm{C}$ anode. AEMWE operation required a $310 \mathrm{mV}$ lower overpotential, or a cell voltage of $1.91 \mathrm{~V}$, at a current density of $400 \mathrm{~mA} / \mathrm{cm}^{2}$ when coupled to a Pt cathode [33].

In the development of AEM and AEMWE devices, Proton reported a cheap anion-conducting membrane based on PSF in collaboration with the Illinois Institute of Technology [13]. PSF was selected as the base material of the membrane because it is mechanically strong, inexpensive, chemically stable under oxidative conditions, and easy to process into AEMs. An MEA was fabricated with ruthenate pyrochlores $\left(2.5 \mathrm{mg} / \mathrm{cm}^{2}\right)$ on carbon paper as the anode, PSFtrimethylammonium $\left(\mathrm{TMA}^{+}\right)$as the $\mathrm{AEM}$, and $\mathrm{Pt}$
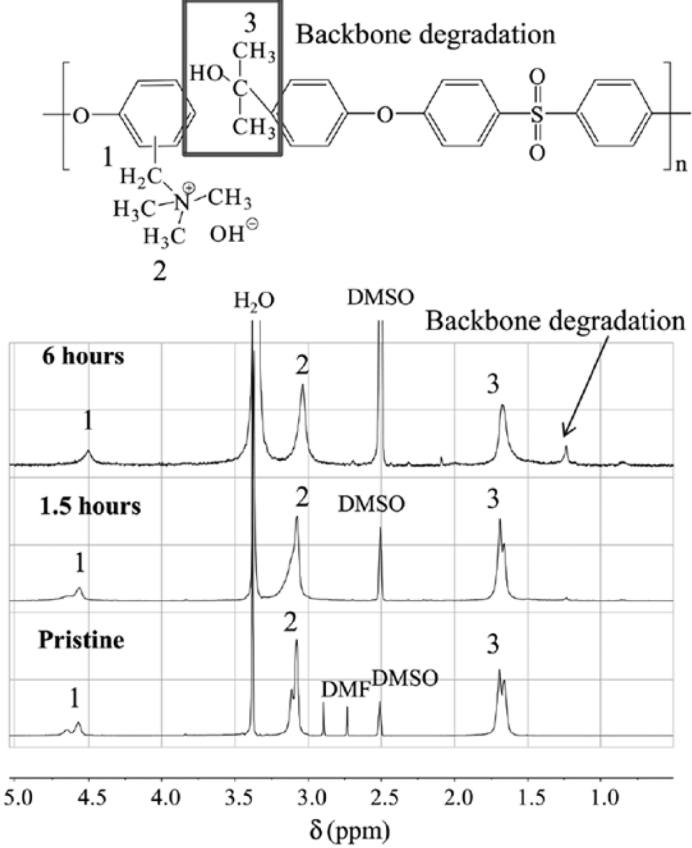

Fig. 4. Proton nuclear magnetic resonance $\left({ }^{1} \mathrm{H}-\mathrm{NMR}\right)$ spectra of pristine (before use in water electrolysis) and post-mortem AEMWE device samples after three polarization runs (approximately $1.5 \mathrm{~h}$ continuous operation) and after continuous operation at $200 \mathrm{~mA} / \mathrm{cm}^{2}$ for $6 \mathrm{~h}$ (reproduced from ref. [13] with permission from the Royal Society of Chemistry).

black $\left(2.5 \mathrm{mg} / \mathrm{cm}^{2}\right)$ on carbon paper as the cathode. Water electrolysis provided a current density of $400 \mathrm{~mA} / \mathrm{cm}^{2}$ at $1.8 \mathrm{~V}$ using ultrapure water $(1.8 \mathrm{M} \Omega)$ 
as the reactant at $50^{\circ} \mathrm{C}$. Although this performance is eligible for commercialized $\mathrm{H}_{2}$ production, either backbone degradation or quaternary carbon hydrolysis occurred in long-term testing after approximately $6 \mathrm{~h}$, making the system unsuitable for commercialization (Fig. 4). It is widely known that PSF-based AEMs degrade in alkaline solutions; further work remains necessary to develop a deployable and inexpensive AEM.

\section{Operating Conditions of AEMWE Single Cell}

The cell performance of AEMWE devices are highly dependent on operating conditions such as cell temperature, electrolyte solution, and feed type. Operating the cell at a higher temperature improves the reaction kinetics $[24,25,28]$. Introducing a basic electrolyte solution instead of neutral water enhances the $\mathrm{OH}^{-}$conduction and reduces the Ohmic potential drop $[25,26]$. Single-sided (supplying the feed to either the anode or cathode) or double-sided (supplying the feed to both the anode and cathode) feeding affects the Ohmic resistance of the MEA [26]. The operation conditions should also be determined considering the stability and durability of the electrolysis device. At a temperature exceeding the thermal stability range of a membrane, the polymer backbone or functional groups may degrade; with the introduction of a highly concentrated alkali solution, the degradation of the membrane is accelerated [30,34], which causes MEA performance degradation. Therefore, operation at appropriate conditions is essential for both the cell performance and the stability of materials employed in the AEMWE device. In this section, the operating conditions of AEMWE devices reported in the literature are briefly reviewed to clarify the effects on the electrolysis performance.

\subsection{Cell Temperature}

The cell performance of electrochemical devices is generally improved with increasing temperature because of improvements in electrode kinetics, ion conductivity, and mass transportation. However, most AEMWE cells are operated at lower temperatures, below $55^{\circ} \mathrm{C}[13,24,26,28,30,35-43]$, mainly because of the thermal stability of the AEMs. Only a few studies have conducted water electrolysis experiments at temperatures above $70^{\circ} \mathrm{C}[23,25,28,44]$.

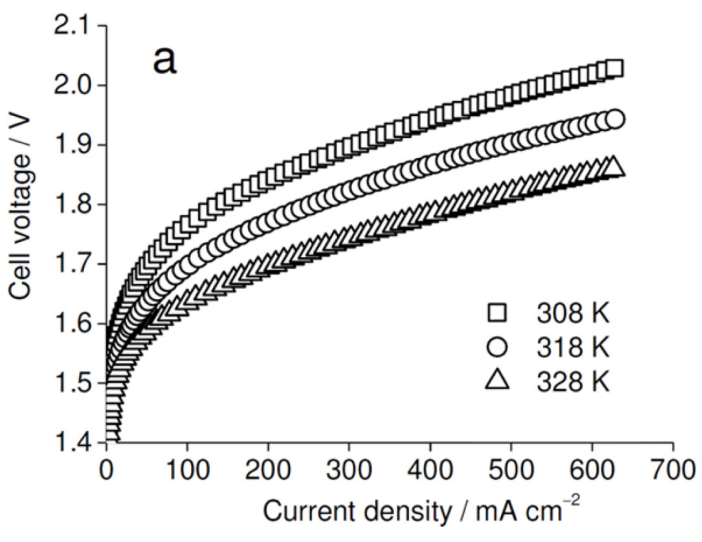

Fig. 5. Polarization curves of AEMWE with a 1 wt.\% $\mathrm{K}_{2} \mathrm{CO}_{3}$ electrolyte solution at various temperatures (reproduced from ref. [24] with permission from Wiley$\mathrm{VCH})$.

Pavel et al. studied the cell voltage dependence on operating cell temperature at 35,45 , and $55^{\circ} \mathrm{C}$ with a 1 wt. $\% \mathrm{~K}_{2} \mathrm{CO}_{3}$ aqueous solution, as shown in Fig. 5 [24]. With increased operating temperature, the cell voltage reduces linearly, with a reduction of approximately $80 \mathrm{mV}$ for each $10^{\circ} \mathrm{C}$ increase at $400 \mathrm{~mA} /$ $\mathrm{cm}^{2}$ [24]. Seetaraman et al. also studied the performance dependence on operating cell temperature from 30 to $90^{\circ} \mathrm{C}$ with a $5.36 \mathrm{M} \mathrm{KOH}$ solution [28]. The current density or device activity was non-linearly increased with increasing cell operating temperature; the current density increase became smaller at higher temperatures [28]. In brief, the operation temperature should be determined with consideration of the device performance, stability, and system efficiency, including the electric and thermal energy utilization.

\subsection{Feed Solution}

The performance and durability of water electrolysis devices are affected by the acidity, ionic conductivity, and chemical reactivity of the solution supplied to the device. For example, the ion conductivity of the feed solution directly influences the AEMWE performance [2,3]. In AEMWE, $\mathrm{KOH}$ is often used as the electrolyte for its high conductivity of $38 \mathrm{mS} /$ $\mathrm{cm}$ for $1 \mathrm{wt} . \%$ aqueous $\mathrm{KOH}[23,24,26,28,38,43]$. In AEMWE, the current density generally increases with increasing in solution alkalinity, accompanied by enhanced ion conductivity. For example, the conductivity of the $\mathrm{KOH}$ aqueous solution is increased 
from 20.0 to $178 \mathrm{mS} / \mathrm{cm}$ as the electrolyte concentration increases from 0.5 to $5 \mathrm{wt} . \%$ [4]. However, material degradation is also accelerated in more basic solutions, causing the system stability and durability to suffer $[30,42]$.

The effects of the feed solution properties on the performance and stability of AEMWE devices have been examined using different concentrations and basicity of electrolyte solutions. Zeng and Zhao obtained a high current density of $530 \mathrm{~mA} / \mathrm{cm}^{2}$ at $1.8 \mathrm{~V}$ by changing the anode feed from deionized water to $0.1 \mathrm{M} \mathrm{NaOH}$, as shown in Fig. 6 [25]. The internal resistances were decreased from 8.39 to $3.27 \Omega \mathrm{cm}^{2}$ with increases in the $\mathrm{pH}$ from 8.51 $\left(0.1 \mathrm{M} \mathrm{NaHCO}_{3}\right)$ to $12.63(0.1 \mathrm{M} \mathrm{NaOH})$, demonstrating that ionic resistance was significantly affected by the electrolyte $\mathrm{pH}$ [25]. A detailed investigation on the effect of basicity and different anions in electrolyte solutions was also performed by Pavel et al. [24]. In the study, $1 \mathrm{M} \mathrm{KOH}, 1$ wt. $\% \mathrm{~K}_{2} \mathrm{CO}_{3}$, and 1 wt. $\% \mathrm{~K}_{2} \mathrm{CO}_{3} / \mathrm{KHCO}_{3}$ were supplied to the anode, with solution conductivities of 194, 15.8, and $12.9 \mathrm{mS} \mathrm{cm}^{-1}$ for $\mathrm{pH}$ values of $14,11.2$, and 10.2 , respectively. The highest current density was obtained with a single cell supplied with $\mathrm{KOH}$ solution $\left(490 \mathrm{~mA} / \mathrm{cm}^{2}\right.$ at $\left.1.8 \mathrm{~V}\right)$, as shown in Fig. 7. However, enhanced stability was achieved by introducing 1 wt. $\% \mathrm{~K}_{2} \mathrm{CO}_{3}$ or $\mathrm{K}_{2} \mathrm{CO}_{3} / \mathrm{KHCO}_{3}$ solution as the electrolyte, as shown by tests conducted for $1000 \mathrm{~h}$ of constant current operation at $470 \mathrm{~mA} / \mathrm{cm}^{2}$, in which carbonization was insignificant [24].

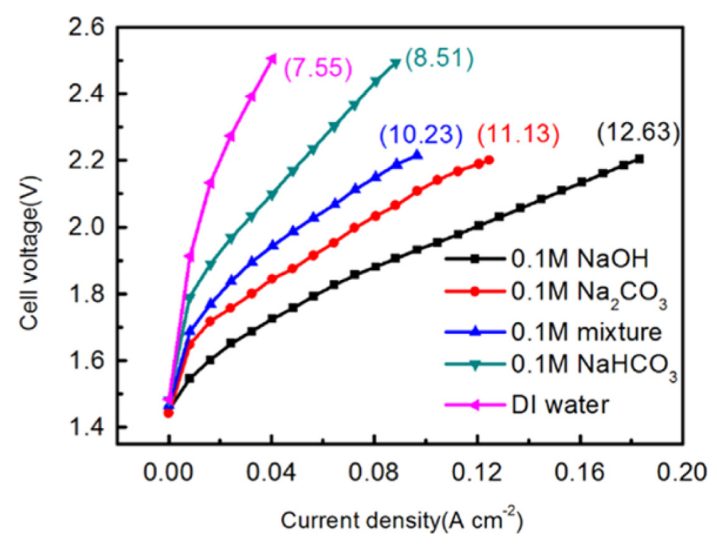

Fig. 6. Polarization curves with various electrolyte feed for integrated inorganic MEA with layered double hydroxides at $70^{\circ} \mathrm{C}$ (reproduced from ref. [25] with permission from Elsevier).

\subsection{Feed Configuration}

The feed configurations of AEMWE cells are important in determining the $\mathrm{H}_{2}$ purity at the cathode and mass transport for HER and OER in water electrolysis. AEMWE was studied under varied feed configurations, such as double-side feeding to both the anode and cathode $[23,44]$ and single-side feeding to either the anode $[13,24,26,41]$ or the cathode $[26,38,43]$ to investigate the complex phenomena occurring in electrochemical devices. The single-side supply to the anode is advantageous for dry $\mathrm{H}_{2}$ gas collection at the cathode, eliminating extra processing to separate the produced $\mathrm{H}_{2}$ from liquid reactants. Leng et al. conducted a study of the performance dependence of AEMWE on feed types [26]. In Fig. 8, the single-side feed to the anode (Case 2) shows a longer lifetime of $317 \mathrm{~h}$ than the single-side feed to the cathode (Case 1, $196 \mathrm{~h}$ ). Moreover, a lifetime of $>535 \mathrm{~h}$ is observed when supplying deionized water to the cathode for the first $2 \mathrm{~h}$ before changing to anode-only feeding for the remaining time (Case 3 ). They observed a longterm performance reduction accompanied by the increase of high-frequency resistance in electrochemical impedance spectroscopy, indicating the close relationship between ohmic resistance and performance degradation [26]. However, it was unclear whether the performance reduction was caused by the degradation of the membrane or ionomer, or by the deterioration of the interfaces between the catalyst layers and AEM.

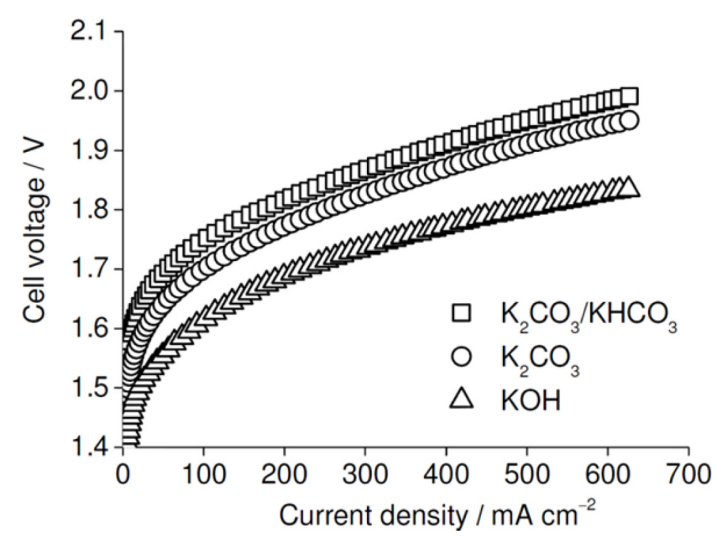

Fig. 7. Polarization curves obtained using different electrolyte solutions with the commercial membrane (A201, Tokuyama)-based MEA at $45^{\circ} \mathrm{C}$ (reproduced from ref. [24] with permission from Wiley-VCH). 


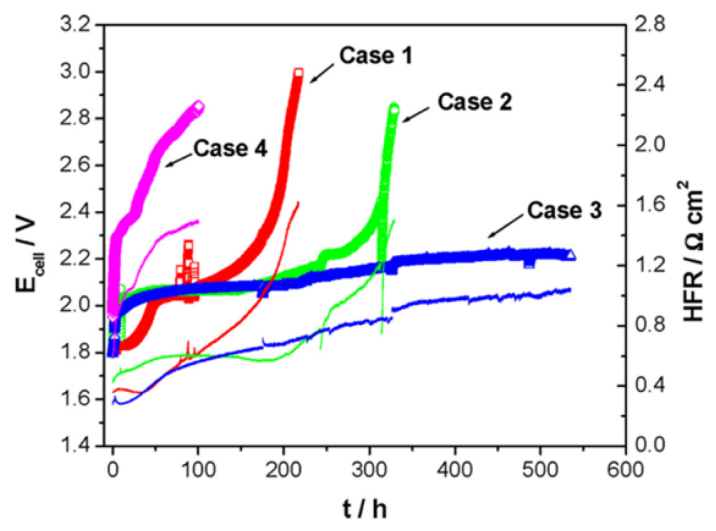

Fig. 8. Performance regarding feed type: Case 1 -cathode feed, Case 2-anode feed, Case 3-deionized water fed to the cathode for $2 \mathrm{~h}$ followed by anode feed, and Case 4anode feed but with a different MEA. An electrode fabricated with A-Radel ionomer was used in Cases 1, 2, and 3, while As-4 ionomer was employed in the MEA for Case 4 (reproduced from ref. [26] with permission from the American Chemical Society).

\section{Conclusions and Outlook}

Water electrolysis has long been studied as a method for clean $\mathrm{H}_{2}$ production, and alkaline liquid electrolysis devices have been commercially deployed for cost-effective water splitting. Proton exchange membrane water electrolysis has also been studied to produce high-pressure $\mathrm{H}_{2}$ with the versatility to utilize intermittent renewable energy sources. However, proton exchange membrane water electrolysis requires expensive precious-metal catalysts and fluorinated membranes for the acidic HER and OER. AEMWE has the advantages of both methods, realizing cost-effective water electrolysis in basic conditions using non-precious catalysts and high-pressure $\mathrm{H}_{2}$ production by membrane electrode reactor employing AEMs. Acta S.p.A. utilizes inexpensive $\mathrm{Ni} /\left(\mathrm{CeO}_{2}-\mathrm{La}_{2} \mathrm{O}_{3}\right) / \mathrm{C}$ and $\mathrm{CuCoO}_{\mathrm{x}}$ catalysts for HER and OER, while Proton Onsite uses $\mathrm{LiCoO}_{2}$ as an OER catalyst. AEMs based on PE and PSF were also investigated by these companies for the development of robust and highly conductive anion-conducting electrolytes. In addition, many factors, including the operating temperature, electrolyte concentration, and solution acidity, significantly affect the AEMWE performance. In general, higher operation temperatures increase the reaction rate of water splitting by facili- tating the reaction kinetics. Electrolyte conductivity is also enhanced with an increased ion concentration in the solution. In addition, the feeding configuration of the supplied solution can affect the mass transport and overall performance, including the device stability. However, the performance of a state-of-the-art AEMWE device of $530 \mathrm{~mA} / \mathrm{cm}^{2}$ at $1.8 \mathrm{~V}$ and a reported lifetime of $1000 \mathrm{~h}$ remain insufficient for industrial needs. Further study of electrolysis devices is necessary to improve the performance and durability of AEMWE.

\section{Acknowledgement}

This work was supported by the New \& Renewable Energy Core Technology Program of the Korea Institute of Energy Technology Evaluation and Planning (KETEP), granted financial resource from the Ministry of Trade, Industry \& Energy, Republic of Korea (No. 20143010031770 and No. 20153010041750). This study was also financially supported by the KIST through the Institutional Project.

\section{References}

[1] B. Obama, Science, 2017, 355(6321), 126-129.

[2] L. Barreto, A. Makihira, K. Riahi, Int. J. Hydrogen Energy, 2003, 28(3), 267-284.

[3] U. Babic, M. Suermann, F.N. Büchi, L. Gubler, T.J. Schmidt, J. Electrochem. Soc., 2017, 164(4), F387-F399.

[4] J.R. McKone, N.S. Lewis, H.B. Gray, Chem. Mater, 2014, 26(1), 407-414.

[5] J.A. Turner, Science, 2004, 305(5686), 972-974.

[6] J.O. Bokris, T. Otagawa, J. Phys. Chem., 1983, 87(15), 2960-2971.

[7] C.C.L. McCrory, S. Jung, J.C. Peters, T.F. Jaramillo, J. Am. Chem. Soc., 2013, 135(45), 16977-16987.

[8] C. Xiang, K.M. Papadantonakis, N.S. Lewis, Mater. Horizons 2016, 3(3), 169-173.

[9] M.K. Cho, H.-Y. Park, S. Choe, S.J. Yoo, J.Y. Kim, H.J. Kim, D. Henkensmeier, S.Y. Lee, Y.-E. Sung, H.S. Park, J.H. Jang J. Power Sources, 2017, 347, 283-290.

[10] D. Zang, K. Zeng, Prog. Energy Combust. Sci., 2010, 36,(3), 307-326.

[11] D. Pletcher, X. Li, Int. J. Hydrog. Energy, 2011, 36(23), 15089-15104.

[12] M.A. Laguna-Bercero, J. Power Sources, 2012, 203, 416.

[13] J. Parrondo, C.G. Arges, M. Niedzwiecki, E.B. Anderson, K.E. Ayers, V. Ramani, RSC Adv, 2014, 4(19), 9875-9879.

[14] H. Vandenborre, R. Leysen, H. Nackaerts, D. Van der 
Eecken, Ph. Van Asbroeck, W. Smets, J. Piepers Int. J. Hydrog. Energy, 1985, 10(11), 719-726.

[15] S. A. Grigoriev, P. Millet, S.V. Korobtsev, V.I. Porembskiy, M. Pepic, C. Etievant, C. Puyenchet, V.N. Fateev, Int. J. Hydrog. Energy, 2009, 34(14), 5986-5991.

[16] T. Smolinka, 18th World Hydrog. Energy Conf. 2010 Essen, 2010.

[17] J.E. Genovese, K. Harg, M. Paster, J.A. Turner, Independent Review Panel Summary Report, 2009.

[18] A. Irshad, N. Munichandraiah, ACS Appl. Mater. Interfaces, 2015, 7(29), 15765-15776.

[19] H. Osgood, S.V. Devaguptapu, H. Xu, J. Cho, G. Wu, Nano Today, 2016, 11(5), 601-625.

[20] M. Gong, D.-Y. Wang, C.-C. Chen, B.-J. Hwang, H. Dai, Nano Research, 2016, 9(1), 28-46.

[21] M.K. Bates, Q. Jia, N. Ramaswamy, R.J. Allen, S. Mukerjee, J. Phys. Chem. C, 2015, 119(10), 5467-5477.

[22] S. Jung, C.C.L. McCrory, I.M. Ferrer, J.C. Peters, T.F. Jaramillo, J. Mater. Chem. A, 2016, 4(8), 3068-3076.

[23] D. Aili, M.K. Hansen, R.F. Renzaho, Q. Li, E. Christensen, J.O. Jensen, N.J. Bjerrum, J. Membr. Sci., 2013, 447, 424-432.

[24] C.C. Pavel, F. Cecconi, C. Emiliani, S. Santiccioli, A. Scaffidi, S. Catanorchi, M. Comotti, Angew. Chem. Int. Ed., 2014, 53(5), 1378-1381.

[25] L. Zeng, T.S. Zhao, Nano Energy, 2015, 11, 110-118.

[26] Y. Leng, G. Chen, A.J. Mendoza, T.B. Tighe, M.A. Hickner, C.-Y. Wang, J. Am. Chem. Soc., 2012, 134(22), 9054-9057.

[27] J. Zhang, H. Zhang, J. Wu, J. Zhang, in: Pem Fuel Cell Testing and Diagnosis, Elsevier, Amsterdam, 2013.

[28] S. Seetharaman, R. Balaji, K. Ramya, K.S. Dhathathreyan, M. Velan, Int. J. Hydrog. Energy, 2013, 38(35), 14934-14942.
[29] http://www.actaspa.com/type/hydrogen-production/.

[30] M. Faraj, M. Boccia, H. Miller, F. Martini, S. Borsacchi, M. Geppi, A. Pucci, Int. J. Hydrog. Energy, 2012, 37(20), 14992-15002.

[31] http://www.protononsite.com/hydrogen-fueling.

[32] FY 2015 Annual Progress Report in DOE Hydrogen and Fuel Cell Program.

[33] G. Gardner, J. Al-Sharab, N. Danilovic, Y.B. Go, K. Ayers, M. Greenblatt, G. Charles Dismukes, Energy Environ. Sci., 2016, 9(1), 184-192.

[34] S. Jeong, J. Lee, S. Woo, J. Seo, B. Min, Energies, 2015, 8(7), 7084-7099.

[35] X. Wu, K. Scott, J. Power Sources, 2012, 206, 14-19.

[36] Y.-C. Cao, X. Wu, K. Scott, Int. J. Hydrog. Energy, 2012, 37(12), 9524-9528.

[37] X. Wu, K. Scott, Int. J. Hydrog. Energy, 2013, 38(8), 3123-3129.

[38] S.H. Ahn, B.-S. Lee, I. Choi, S.J. Yoo, H.-J. Kim, E. Cho, D. Henkensmeier, S.W. Nam, S.-K. Kim, J.H. Jang, Appl. Catal. B: Environ., 2014, 154-155, 197-205.

[39] X. Wu, K. Scott, F. Xie, N. Alford, J. Power Sources, 2014, 246, 225-231.

[40] J. Parrondo, V. Ramani, J. Electrochem. Soc., 2014, 161(10), F1015-F1020.

[41] J. Parrondo, M. George, C. Capuano, K.E. Ayers, V. Ramani, J. Mater. Chem. A, 2015, 3(20), 10819-10828.

[42] L.A. Diaz, J. Hnát, N. Heredia, M.M. Bruno, F.A. Viva, M. Paidar, H.R. Corti, K. Bouzek, G.C. Abuin, J. Power Sources, 2016, 312, 128-136.

[43] S.H. Ahn, S.J. Yoo, H.-J. Kim, D. Henkensmeier, S.W. Nam, S.-K. Kim, J.H. Jang, Appl. Catal. B: Environ., 2016, 180, 674-679.

[44] L. Xiao, S. Zhang, J. Pan, C. Yang, M. He, L. Zhuang, J. Lu, Energy Environ Sci., 2012, 5(7), 7869-7871. 